\title{
Serologic host response to Helicobacter pylori and Campylobacter jejuni in socially housed Rhesus macaques (Macaca mulatta)
}

Sabine Kienesberger ${ }^{1 *}$, Guillermo I Perez-Perez ${ }^{1,2}$, Juan L Rivera-Correa ${ }^{5}$, Rafael Tosado-Acevedo ${ }^{6}$, Huilin Li ${ }^{4}$, Andre Dubois ${ }^{7}$, Janis A Gonzalez-Martinez ${ }^{8}$, Maria Gloria Dominguez-Bello ${ }^{1,5}$ and Martin J Blaser ${ }^{1,2,3}$

\begin{abstract}
Background: Helicobacter pylori are successful colonizers of the human gastric mucosa. Colonization increases the risk of peptic ulcer disease and adenocarcinoma. However, potential benefits of H. pylori colonization include protection against early-onset asthma and against gastrointestinal infections. Campylobacter jejuni are a leading cause of bacterial diarrhea and complications include Guillain-Barré syndrome. Here, we describe the development of reliable serological assays to detect antibodies against those two bacteria in Rhesus macaques and investigated their distribution within a social group of monkeys.

Methods: Two cohorts of monkeys were analyzed. The first cohort consisted of 30 monkeys and was used to establish an enzyme-linked immunosorbent assay (ELISA) for $\mathrm{H}$. pylori antibodies detection. To evaluate colonization of those macaques, stomach biopsies were collected and analyzed for the presence of $\mathrm{H}$. pylori by histology and culture. C. jejuni ELISAs were established using human serum with known C. jejuni antibody status. Next, plasma samples of the 89 macaques (Cohort 2) were assayed for antibodies and then statistically analyzed.

Results: An H. pylori lgG ELISA, which was 100\% specific and 93\% sensitive, was established. In contrast, the IgA ELISA was only $82 \%$ specific and $61 \%$ sensitive. The CagA IgG assay was $100 \%$ sensitive and $61 \%$ of the macaques were positive. In cohort 2, 62\% macaques were H. pylori sero-positive and 52\% were CagA positive. The prevalence of H. pylori $\lg G$ and CagA IgG increased with monkey age as described for humans. Of the 89 macaques 52\% showed lgG against $C$. jejuni but in contrast to $H$. pylori, the sero-prevalence was not associated with increasing age. However, there was a drop in the $\lg G$ (but not in $\lg A$ ) mean values between infant and juvenile macaques, similar to trends described in humans.

Conclusions: Rhesus macaques have widespread exposure to H. pylori and C. jejuni, reflecting their social conditions and implying that Rhesus macaques might provide a model to study effects of these two important human mucosal bacteria on a population.
\end{abstract}

Keywords: Helicobacter pylori, Campylobacter jejuni, Rhesus macaques, Antibodies, Sero-prevalence, CagA

\section{Background}

Helicobacter pylori are Gram-negative bacteria that colonize the gastric mucosa of humans across the world. However, H. pylori is disappearing from populations in developed countries [1,2]. In developing countries, up to $90 \%$ of the adult population carries the organism $[3,4]$. H. pylori is acquired early in life $[5,6]$ and generally persists unless hosts are treated with antibiotics [1]. Gastric

\footnotetext{
* Correspondence: sabine.kienesberger@nyumc.org

'Department of Medicine, NYU Langone Medical Center, New York, NY, USA Full list of author information is available at the end of the article
}

H. pylori colonization increases risk of peptic ulcer disease as well as adenocarcinoma of the distal stomach [7]. In addition to negative effects late in life, there is now evidence that $H$. pylori may protect against early-onset asthma [8-10] and gastrointestinal infections [11-13], thus providing benefits early in life. Because Rhesus macaques usually are persistently colonized with $\mathrm{H}$. pylori and develop chronic gastritis [13,14], they represent a model to study host interactions.

Campylobacter jejuni are Gram-negative bacteria that are among the leading causes of acute gastroenteritis

\section{Biomed Central}


worldwide [15]. Sequelae of $C$. jejuni infections may include the Guillain-Barré syndrome and reactive arthritis [16-18]. C. jejuni infections are known to be highly prevalent within monkey colonies, especially when the animals are living under non-natural conditions [19]. Despite recent advances [20-24], the colonization dynamics of $H$. pylori and $C$. jejuni in macaques in relation to infection in humans have been little examined. The purpose of this study was to (I) establish reliable serological assays to detect monkey antibodies to H. pyloriand $C$. jejuni-specific antigens and (II) to investigate the sero-prevalence of $H$. pylori and C. jejuni in a socialgroup of Rhesus macaques. We hypothesized that a group of monkeys with constant contact with each other would be manifested by a high prevalence of responses to these enteric organisms, similar to those shown by humans before the introduction of antibiotics and better hygienic standards. Such assays could provide models to study $H$. pylori spread, eradication, and putative positive and negative effects in individuals and in populations.

\section{Results \\ Verification of ELISA for determination of H. pylori sero-status using Rhesus macaque Cohort 1}

Cohort 1 was used to establish reliable cut-off values for H. pylori sero-positivity to analyze Cohort 2. According to endoscopy performed on the 30 animals in Cohort 1 , 13 macaques were negative for $H$. pylori and 17 were positive. Specific plasma IgG to $H$. pylori was substantially higher in animals who had been shown by endoscopy to be colonized compared to negative macaques (Table 1). Having a positive IgG antibody (ODR $>0.340$ ) determination was $100 \%$ sensitive but it was only $70 \%$ specific for colonization when endoscopy was used as the gold standard (Table 2). Because of presumed falsely negative endoscopic results observed in the initial samples, we defined $H$. pylori-positivity by either a positive endoscopy or IgG ODR $>0.340$ on the initial plasma. When we tested these combined criteria for 40 followup plasma obtained from the same animals, we found that this combination was highly accurate (93\% sensitive, $100 \%$ specific). Four macaques were $H$. pylori biopsynegative on the initial examination but had high CagA, IgG, and IgA values as well as high gastric inflammation scores (Table 1). The CagA assay was highly specific $(100 \%)$ and $61 \%$ of the H. pylori-positive macaques were CagA-positive, which is similar to the prevalence in humans [25-27]. In contrast, the IgA ELISA was only $82 \%$ specific and $61 \%$ sensitive (Table 2). In total, we conclude that determination of the H. pylori IgG status is highly accurate in Rhesus macaques, reflecting the actual $H$. pylori colonization status. As such, we could use it to assess $H$. pylori status in monkeys without endoscopy.

\section{Cohort 2: Sero-prevalence of $H$. pylori is higher in older Rhesus macaques}

First, we examined the ODR-values obtained for the Cohort 2 monkeys. Since the cut-offs obtained from the Cohort 1 macaques and from Cohort 2 were very similar (Table 3), we considered them to be reliable. We then examined the $H$. pylori IgG status in 89 macaques in Cohort 2, using the determined cut-off. Summaries of the data are shown in Table 4 and Figure 1. A total of 58 (62\%) of the 89 Rhesus macaques were $H$. pylori seropositive and the sero-prevalence of $H$. pylori increased with age (Cochran-Armitage Trend Test, $\mathrm{p}<0.0001)$.

\section{H. pylori IgA status correlates with the IgG status only in older Rhesus macaques}

The serum of the 89 animals was also tested for the presence of serum IgA antibodies to $H$. pylori antigens using the IgG-determined status as a standard. An IgA cut-off at 0.39 was considered predictive to determine the $H$. pylori status since it yielded the same percent (64\%) of positivity. Of the 57 macaques determined to be IgA-positive (Figure 1), in the youngest group, only 2 (7\%) monkeys were both IgA and IgG positive, but 9 (38\%) group 2 monkeys, 14 (67\%) group 3 monkeys and 14 (82\%) monkeys of the oldest group showed doublepositive status (Figure 1). Thus, IgG antibodies become more prevalent with age in the $H$. pylori-positive monkeys.

\section{CagA sero-prevalence correlates with $H$. pylori lgG status}

When the Rhesus macaques of Cohort 2 were analyzed with the CagA cut-off established at $0.200,52 \%$ of the macaques were $\mathrm{CagA}+$, similar to the $61 \%$ of $\mathrm{CagA}+$ monkeys of Cohort 1 . As with the H. pylori IgG, the prevalence of CagA antibodies increased with the age of the monkeys (Table 4 and Figure 1) (Cochran-Armitage Trend Test, $\mathrm{p}<0.0001)$. With the exception of the youngest group of Rhesus macaques, the $H$. pylori status closely correlated with the CagA status. Next, we compared the percent of macaques positive for both $\mathrm{H}$. pylori and CagA with those that only were positive for $H$. pylori (Table 4). The ratio of double-positive monkeys increased with age (Figure 1). In total, $36(40 \%)$ of the 89 animals were positive in both assays and 12 (13\%) were only positive for $H$. pylori.

\section{H. pylori IgG and IgA ODR-values and CagA IgG ODR- values are higher in older Rhesus macaques}

If our analysis is correct and sero-prevalence is truly higher in older monkeys, ODR-values and monkey age should be correlated. Linear regression analysis to examine H. pylori IgG and IgA and CagA IgG values in relation to monkey age were performed (Figure 2A-C). For both $H$. pylori IgG and IgA, there were significant trends 
Table $1 \mathrm{H}$. pylori antibody responses and inflammation scores for the 30 Rhesus macaques of Cohort 1

\begin{tabular}{|c|c|c|c|c|c|c|}
\hline \multirow{2}{*}{\multicolumn{2}{|c|}{$\begin{array}{c}\text { Evidence for } \\
\text { H. pylori presence }\end{array}$}} & \multicolumn{5}{|c|}{ Mean $\pm \mathrm{SD}^{a}$} \\
\hline & & \multicolumn{2}{|c|}{ H. pylori } & \multicolumn{2}{|c|}{ CagA } & \multirow[t]{2}{*}{ Inflammation score } \\
\hline Endoscopy & IgG serology & $n$ & $\lg G$ & $\lg A$ & $\lg G$ & \\
\hline- & - & 9 & $0.13 \pm 0.07$ & $0.20 \pm 0.12$ & $0.08 \pm 0.06$ & $1.25 \pm 1.39$ \\
\hline- & + & 4 & $0.75 \pm 0.27$ & $0.66 \pm 0.45$ & $0.41 \pm 0.24$ & $2.25 \pm 0.96$ \\
\hline+ & + & 17 & $1.10 \pm 0.38$ & $0.94 \pm 0.53$ & $0.71 \pm 0.50$ & $4.56 \pm 1.83$ \\
\hline
\end{tabular}

${ }^{a}$ Mean ODR-values were significantly $(\mathrm{p}<0.001)$ different between the known negative $(n=9)$ and the known positive $(n=17)$ monkeys for each antibody response and for inflammation score. Mean values were significantly different between the negative monkeys and the monkeys that were endoscopy negative but IgG positive $(n=4)$ for CagA antibody response $(p<0.02)$ but not for inflammation score.

of higher values with age. The same relationship was obtained for CagA IgG. This remains true after adjusting for gender in the linear regression analysis. Moreover, $H$. pylori IgG levels in female monkeys appear to increase faster as they age compared with males values. Females also had elevated $H$. pylori IgA and CagA IgG levels compared to males throughout their lifetime (not shown). There also were significant gender differences in $H$. pylori IgG sero-prevalence between females and males (Odd ratio $=2.56$, 95\% CI: 1.04-6.32, $\mathrm{p}=0.04$ ) when the total number of monkeys was analyzed. In summary, older Rhesus macaques have higher $H$. pylori IgG and IgA and CagA IgG ODR-values, consistent with a higher prevalence of $H$. pylori and of CagA-positive strains in older monkeys.

\section{CagA status of $\lg A / \lg$ positive Rhesus macaques}

Using a very stringent criterion in which only IgA and IgG double-positive macaques were considered as $H$. pyloripositive (Figure 1), there were 39 (44\%) monkeys that were double-positive. Of these, 26 (67\%) were triple-positive (H. pylori and CagA IgG, and H. pylori IgA).

Table 2 Serological responses to $H$. pylori antigens in initial and follow-up sera from Cohort 1 Rhesus macaques in relation to initial $\boldsymbol{H}$. pylori status

\begin{tabular}{|c|c|c|c|c|c|}
\hline \multirow[b]{3}{*}{ Timing } & \multirow[b]{3}{*}{ Status } & \multirow[b]{3}{*}{ Number of specimens } & \multicolumn{3}{|c|}{ \% positive } \\
\hline & & & \multicolumn{2}{|c|}{ H. pylori } & \multirow{2}{*}{$\frac{\operatorname{CagA}}{\lg G^{d}}$} \\
\hline & & & $\lg G$ & $\lg A^{c}$ & \\
\hline \multirow[t]{2}{*}{ Initial } & $+^{a}$ & 17 & 100 & 88 & 82 \\
\hline & - & 13 & 30 & 23 & 23 \\
\hline \multirow[t]{2}{*}{ Follow-up } & $++^{b}$ & 28 & 93 & 61 & 61 \\
\hline & - & 12 & 0 & 18 & 0 \\
\hline
\end{tabular}

a Positive (colonized) defined as detection of $H$. pylori from culture or histological examination of gastric antral biopsy.

${ }^{b}$ Positive (colonized) defined as detection of $H$. pylori from culture or histological examination of gastric antral biopsy, or presence of lgG ODR (>0.34) in the initial specimen. A total of 40 follow-up serum specimens were available for examination.

' Positive was defined as ODR $>0.4$; based on Mean +2 intervals of SD of values from reference group of uninfected monkeys.

${ }^{d}$ Positive was defined as ODR $>0.2$; based on Mean +2 intervals of SD of values from reference group of uninfected monkeys.

\section{C. jejuni sero-prevalence is not associated with increasing} Rhesus macaque age

We also analyzed $C$. jejuni positivity by using a cut-off value obtained by both testing 26 human samples of known $C$. jejuni status [28], and by using statistical evaluation of Cohort 2 values. A total of 59 monkeys (52\%) showed serum IgG against $C$. jejuni (Figure 3). There was no correlation between age and infection status $(\mathrm{p}=0.23)$. Using stringent criteria, counting only IgA and IgG double-positive monkeys as $C$. jejuni positive (Figure 3), a total of 31 monkeys (35\%) were thus positive. The IgA and IgG status were not correlated, and C. jejuni sero-positivity also was not agerelated (Cochran-Armitage Trend Test, $\mathrm{p}=0.79$ ). There was no positive or negative association at any age between H. pylori and C. jejuni IgG status.

\section{C. jejuni IgG and IgA ODR-values do not increase with Rhesus macaque age}

As described for $H$. pylori, using regression analysis, we determined whether IgG and IgA ODR-values change with age. In contrast to $H$. pylori, $C$. jejuni IgG or IgA values are not higher in older macaques (Figure 2D-E). When $C$. jejuni IgG mean values for each group were analyzed separately, there was a significant difference $(p=0.004)$ between groups 1 and 2, but there was no drop for IgA (Figure 2F). A similar trend has been described in humans $[29,30]$. The IgA median stayed constant for the first three groups and rose in the oldest Rhesus macaques. In contrast to $H$. pylori colonization, C. jejuni positivity did not substantially increase with age.

Table 3 Summary of threshold cut-off values in groups of Rhesus macaques of unknown $\boldsymbol{H}$. pylori status

\begin{tabular}{|c|c|c|c|}
\hline \multirow[b]{2}{*}{ Antibody } & \multicolumn{2}{|c|}{ H. pylori } & \multirow{2}{*}{$\begin{array}{c}\text { CagA } \\
\lg G\end{array}$} \\
\hline & $\lg G$ & $\lg A$ & \\
\hline Cut-off from Cohort 1 & 0.340 & 0.440 & 0.200 \\
\hline Negative $(0.000-0.299)^{b}$ & 0.344 & 0.363 & 0.198 \\
\hline Positive $(0.400-1.000)^{b}$ & 0.297 & 0.362 & 0.299 \\
\hline Mean Value ${ }^{a}$ & $0.327(0.340)$ & $0.388(0.400)$ & $0.232(0.200)$ \\
\hline Standard Deviation & 0.024 & 0.057 & 0.050 \\
\hline
\end{tabular}

${ }^{a}$ Values in ( ) describe the actual ODR-cut-off values used to analyze Cohort 2. ${ }^{b}$ As calculated, for Cohort 2. 
Table 4 H. pylori positivity of 89 Rhesus macaques by age $^{a}$

\begin{tabular}{|c|c|c|c|c|c|c|}
\hline \multicolumn{7}{|c|}{ Group 1 - Infants (0.5-0.9 years) $(n=27)$} \\
\hline & $\lg G+b$ & CagA+ & $\operatorname{lgG}+/$ CagA+ & $\operatorname{lgG}+/$ cagA- & $\operatorname{lgG}-/ \mathrm{CagA}+$ & $\operatorname{lgG-c}$ \\
\hline Total \# & 10 & 6 & 2 & 5 & 4 & 17 \\
\hline$\%$ & 37 & 22 & 7 & 16 & 15 & 63 \\
\hline
\end{tabular}

Group 2 - Juvenile (1.0-2.9 years) $(n=24)$

$\operatorname{lgG}+{ }^{b} \mathrm{Cag} A+\lg \mathrm{G}+/ \mathrm{Cag} \mathrm{A}+\lg \mathrm{G}+/ \mathrm{cag} \mathrm{A}-\operatorname{lgG}-/ \mathrm{Cag} \mathrm{A}+\operatorname{lgG} \mathrm{c}^{c}$

$\begin{array}{lllllll}\text { Total \# } & 13 & 11 & 8 & 2 & 3 & 11 \\ \% & \mathbf{5 4} & \mathbf{4 6} & \mathbf{3 3} & \mathbf{8} & \mathbf{1 3} & \mathbf{4 6}\end{array}$

Group 3 - Young adult (3.0-9.9 years) $(n=21)$

$\operatorname{lgG}+{ }^{b} \mathrm{Cag} A+\lg \mathrm{G}+/ \mathrm{Cag} \mathrm{A}+\lg \mathrm{G}+/ \mathrm{cag} \mathrm{A}-\operatorname{lgG}-/ \mathrm{Cag} \mathrm{A}+\operatorname{lgG} \mathrm{c}^{c}$

Total \# $18 \quad 16 \quad 13 \quad 13 \quad 2 \quad 303$

$\begin{array}{lllllll}\% & 86 & 76 & 62 & 10 & 14 & 14\end{array}$

Group 4 - Adult $(\geq 10$ years) $(n=17)$

$\operatorname{lgG}+{ }^{b} \mathrm{CagA}+\lg \mathrm{C}+/ \mathrm{Cag} \mathrm{A}+\lg \mathrm{lg}+/ \mathrm{cag} \mathrm{A}-\operatorname{lgG}-/ \mathrm{CagA}+\operatorname{lgG}-c$

$\begin{array}{lllllll}\text { Total \# } & 16 & 13 & 13 & 3 & 0 & 1 \\ \% & \mathbf{9 4} & \mathbf{7 6} & \mathbf{7 6} & \mathbf{1 8} & \mathbf{0} & \mathbf{6}\end{array}$

Total $(\mathbf{n}=89)$

$\operatorname{lgG}+{ }^{b} \mathrm{CagA}+\lg \mathrm{G}+/ \mathrm{CagA}+\operatorname{lgG}+/ \mathrm{cag} A-\operatorname{lgG}-/ \mathrm{CagA}+\operatorname{lgG}-$

$\begin{array}{lllllll}\text { Total \# } & 57 & 46 & 36 & 12 & 10 & 32\end{array}$

$\begin{array}{lllllll}\% & 64 & 52 & 40 & 13 & 11 & 36\end{array}$

${ }^{a}$ From the total of 94 Rhesus macaques studied, 5 that were $<0.5$ years of age were excluded.

${ }^{b}$ positive in either the $H$. pylori or CagA lgG assay.

${ }^{c}$ negative in both the $H$. pylori and CagA IgG assays.

\section{Discussion}

The original habitats of Rhesus macaques range from Central to Southeast Asia [31]. However, populations of Rhesus macaques have been living in captivity for

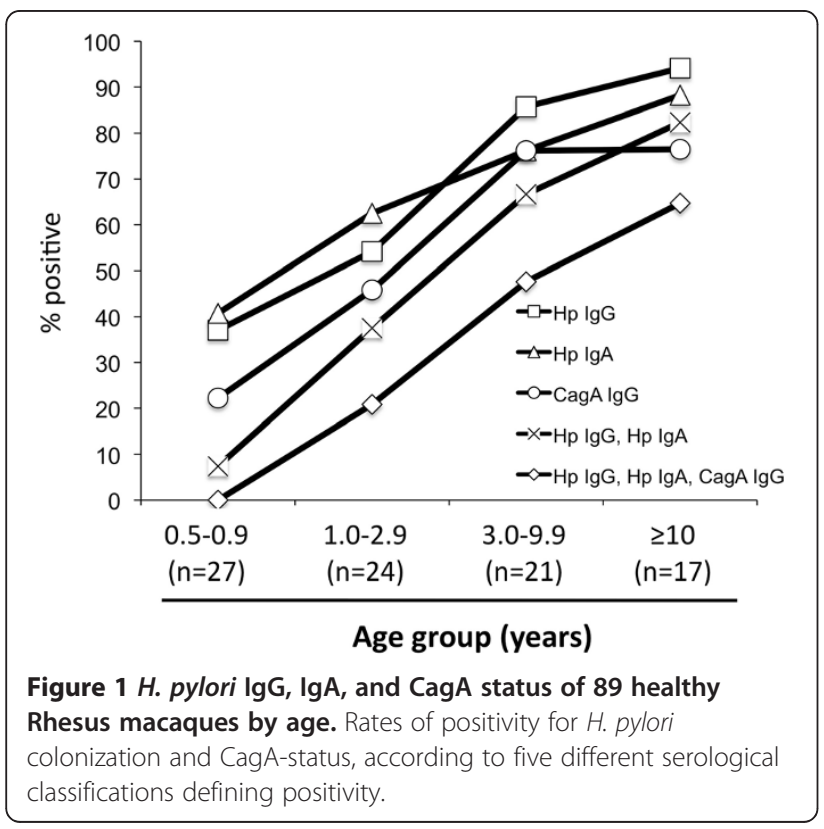

generations, since they are the most important nonhuman primates used for medical and biological research [32-36]. For this study, we analyzed gastric biopsies and blood samples from the animal facility at the Uniformed Services University of the Health Sciences, to establish reliable cut-off values for detecting $H$. pylori antibodies (Cohort 1). To investigate the sero-prevalence of responses to $H$. pylori and C. jejuni antigens in social Rhesus macaques, we studied blood samples routinely taken from a population of animals living together in one outdoor cage in the Caribbean Primate Research Center since 1984 (Cohort 2). We sought to determine how prevalent $H$. pylori and $C$. jejuni-specific antibodies are in a group of Rhesus macaques to evaluate whether the colonization rates of monkeys are similar to human populations.

Although $H$. pylori and C. jejuni are phylogenetically close, they differ substantially in the nature of their antigens [37], even including conserved proteins like their heat-shock protein 60 [38]. Among other factors, flagellae proteins [39], adhesins and outer membrane proteins differ considerably between $C$. jejuni and $H$. pylori [40]. In this study we used water-extracted proteins as antigens. Potential cross-reactions between $H$. pylori and Campylobacter antigens have been addressed in previous studies $[41,42]$ and are considered to be of minor significance [43]. Moreover, the immune response to CagA is specific for $H$. pylori and no cross-reactions have been described.

Using the biopsy and blood samples from Cohort 1, we were able to establish ELISAs that were 100\% specific and $93 \%$ sensitive for $H$. pylori IgG detection, and 100\% sensitive for CagA IgG. In contrast, the IgA ELISA was much less specific and sensitive and as is the case with humans [44], not sufficiently accurate for classification of $H$. pylori status in Rhesus macaques.

The determined ELISA parameters were used to evaluate Cohort 2 for $H$. pylori prevalence. In developed countries, $H$. pylori is disappearing [1,2] but in developing countries, $H$. pylori prevalence remains high $[3,4]$. The prevalence of $H$. pylori in monkeys clearly increases with age. In the oldest monkeys, positivity increased to 94\%. Even using a more stringent IgG and IgA double positive criterion to classify monkeys as $H$. pylori-colonized, the trends remain the same and the same agedependency was observed for the CagA IgG ELISA. Parallel age trends are commonly observed in studies conducted in human populations [27,45]. However, in contrast to humans, younger Rhesus macaques have the same likelihood to have a CagA-positive strain as do the macaques in the oldest group. Comparing double- (44\%) and triple- $(29 \%)$ positive rates, about $67 \%$ of the $H$. pylori-positive monkeys were colonized with a CagA + strain. This is comparable to the situation among humans in 


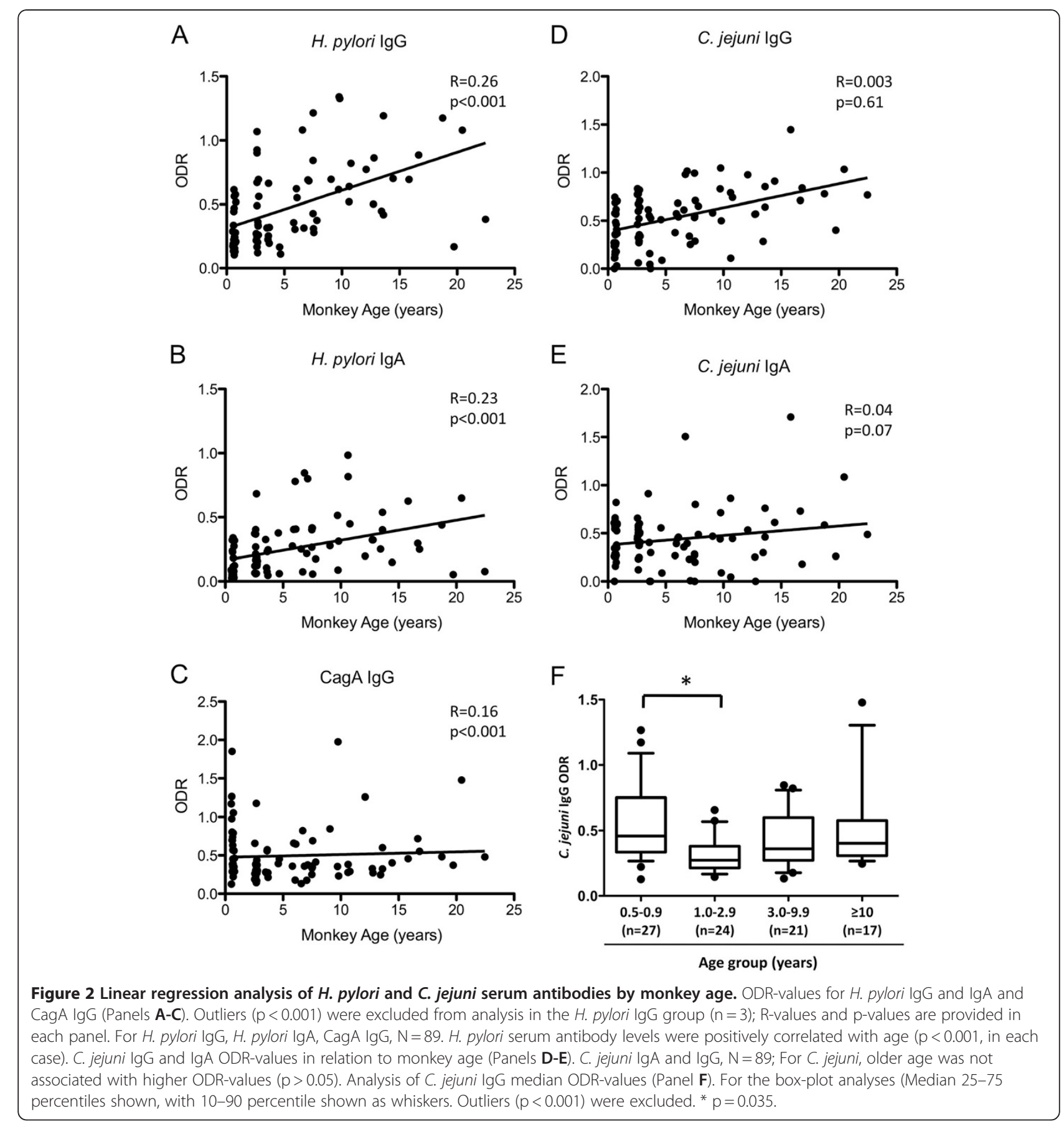

developing countries $[27,45]$. In summary, the socially living Rhesus macaques in captivity resemble the premodern situation for $H$. pylori colonization. One possible route of acquiring $H$. pylori in younger monkeys is by oral-oral contact [46] with older monkeys. Free-living monkeys and monkeys in captivity have close contact with each other, making it impossible to trace infection routes back to parents, siblings, aunts or playmates, without the ability to genotype the strains. How the Rhesus macaques originally acquired $H$. pylori also remains unclear.
Genotyping would help to elucidate whether the strains are of human origin, and whether such strains were introduced into the Rhesus macaque population before or after they were captured in 1938 and brought to Cayo Santiago Island (i.e. carrying an Asian strain). Strain isolation from gastric biopsies and multi-locus sequence typing (MLST) analysis could help answer these questions.

To determine the cut-off values for the $C$. jejuni ELISA, we used blood samples from humans of known C. jejuni status [28]. The tested 94 monkeys did not 


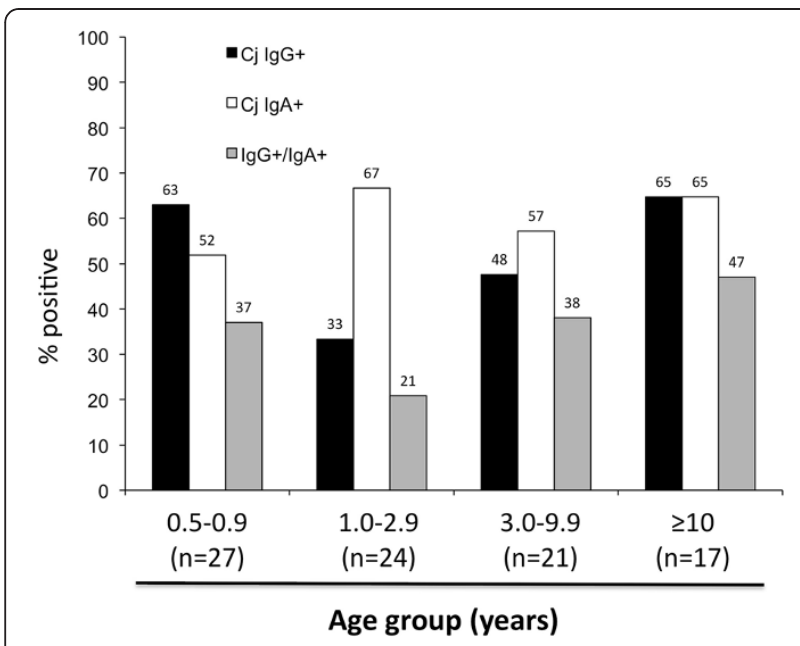

Figure 3 C. jejuni sero-status of 89 healthy Rhesus macaques by age.

show any signs of diarrhea at the time of sampling and had no evidence of acute infection. In contrast to $H$. pylori, there was no correlation between age and $C$. jejuni seropositivity. In general, the prevalence of $C$. jejuni IgG was equally high in all the groups, with a significant drop of prevalence of IgG antibodies in juvenile Rhesus macaques. However, a high prevalence of $C$. jejuni IgA was observed in that group. In areas in which $C$. jejuni infection is hyperendemic and infection is recurrent, young children develop high levels of specific serum IgG antibodies. With continued exposure, IgG levels wane and IgA levels rise [29,30], and the duration of colonization diminishes reflecting development of gut immunity [36]. The drop in IgG between infant and juvenile macaques that we observed is consistent with this phenomenon. As in humans, C. jejuni causes transient infection in Rhesus macaques and specific antibodies are detected in convalescence [47].

\section{Conclusions}

This study describes the distribution of $H$. pylori and $C$. jejuni-specific antibodies in a social group of Rhesus macaques living in captivity. The study indicates that Rhesus macaques have widespread exposure to two important human mucosal bacteria, suggesting that they may provide a good model to study short- and longterm effects of $C$. jejuni and $H$. pylori colonization, respectively, in a population. The ELISAs that were established provide methods to determine the $H$. pylori colonization status and prior exposure to $C$. jejuni in Rhesus macaques.

\section{Methods}

\section{Animals studies}

Two cohorts of Rhesus macaques were studied. Cohort 1 consisted of 30 domestic male Rhesus macaques
(Macaca mulatta) [2 to 7 years old and weighing 3$5 \mathrm{~kg}$ ] from the animal facility at the Uniformed Service University of the Health Sciences in Bethesda, Maryland. Samples were collected between January 1988 to May 1995. Upon arrival to the facility, these monkeys had been quarantined for 90 days in individual stainless steel cages in conventional holding rooms of the animal facility [approved by The American Association for Accreditation of Laboratory Animal Care (AALAC)] and were subsequently kept in similar individual cages. Animals were provided with tap water ad libitum, commercial primate chow, and fruit. All subsequent studies were performed after an overnight fast, between 8 am and noon.

The studied social group of monkeys (Cohort 2) consisted of 94 Rhesus macaques housed in the Caribbean Primate Research Center in Sabana Seca, Puerto Rico. These animals are descendants of monkeys brought to the Research Center in 1984 from the free-ranging colony on Cayo Santiago Island. They are co-housed and are in constant contact with one another. Serum samples were collected between December 2008 and April 2010. The studies were performed in a cross-sectional design for determination of $H$. pylori and $C$. jejuni status, according to age. The Rhesus macaques (Cohort 2, $\mathrm{N}=94,60$ females, 34 males) were assigned to groups according to age: group 1 (Infant) includes monkeys $<1$ year $[\mathrm{N}=32$ (17 females/ 15 males)]; group 2 (Juvenile) monkeys were 1.0-2.9 years $[\mathrm{N}=24(18 / 6)]$; group 3 (Young Adult) monkeys were 3.09.9 years $[\mathrm{N}=21(12 / 9)]$ and group 4 (Adult) consisted of all monkeys $\geq 10$ years of age $[\mathrm{N}=17(13 / 4)]$. Of the 32 monkeys in group 1 , five ( 3 female, 2 male) $<0.5$ years were excluded from serological analysis, due to potential maternal antibodies.

\section{Endoscopic procedures and biopsies}

The 30 Rhesus macaques of Cohort 1 underwent gastroduodenal endoscopic examination under general anesthesia, essentially as described [13]. From each animal, six pinch biopsies of the gastric corpus and six from gastric antral mucosa were obtained. Two biopsies from each region were fixed in neutral $10 \%$ buffered formalin and embedded in paraffin. Biopsy sections were stained with haematoxylin and eosin or Genta's method and viewed under $100 \mathrm{x}$ to $1,000 \mathrm{x}$ magnification. The presence of inflamamatory cells in the biopsies was scored on coded slides, as described [47]; as were the presence of stained $H$. pylori organisms, as described [13]. Two other biopsies from antrum and corpus were immediately placed in $0.1 \mathrm{ml}$ sterile $0.9 \% \mathrm{NaCl}$ on ice and processed for $H$. pylori isolation, as described [47]. H. pylori isolates were identified as pinhead-colonies, urease-, oxidase- and catalase-positive, and were Gram-negative curved or "gull-wing" rods. 


\section{Measurement of $\boldsymbol{H}$. pylori-specific antibodies in Cohort 1}

From each Rhesus macaque at the time of each endoscopy, five milliliters of blood was collected in tubes containing $10.5 \mathrm{mg}$ of EDTA and centrifuged; the supernatant plasma was frozen at $-70^{\circ} \mathrm{C}$. The monkey samples were diluted 1:800 for IgG and 1:100 for IgA. Anti-H. pylori immunoglobulin G (IgG) and A (IgA) levels in the plasma were determined, using a modification of a method with high sensitivity and specificity for human $H$. pylori positivity, as described $[13,41]$. In brief, the $H$. pylori antigens, composed of a mixture of protein and lipopolysaccharides from five $H$. pylori strains (ATCC 53722, 53721, 53725, 53726 , and 53727), were obtained by water extraction and sonication, as described [41]. The mixture was diluted in $0.05 \mathrm{M}$ carbonate buffer ( $\mathrm{pH} 9.6)$ to coat each well of a flat-bottom ELISA-plate with $1.0 \mathrm{mg}$ antigen. Plates were coated overnight at $4^{\circ} \mathrm{C}$ and then blocked for $3 \mathrm{~h}$ with $1 \mathrm{x}$ PBS containing 0.05\% Tween-20, $0.1 \mathrm{mg} / \mathrm{ml}$ thimerosal, and $0.1 \%$ gelatin. Serum samples were added and plates were incubated for $1 \mathrm{~h}$ at $37^{\circ} \mathrm{C}$. All washing steps were performed with $1 \mathrm{x}$ PBS containing 0.05\% Tween-20 and $0.1 \mathrm{mg} / \mathrm{ml}$ thimerosal. Goat anti-monkey IgG (gamma chain) or IgA (alpha chain) conjugated to horseradish peroxidase (Rockland Immunochemicals Inc., Gilbertsville, PA) was used as second antibody for detection of responses. A cut-off value was established to distinguish between positive and negative results in the IgG enzymelinked immunosorbent assay (ELISA) by determining ODR-values (optical density ratio). ODRs were determined for each sample by dividing the OD-value of the sample by the OD-value of two positive controls for $H$. pylori and C. jejuni IgA and IgG and one positive control for $H$. pylori CagA, which were included on each ELISA plate as reference specimens. Using 9 Rhesus macaques found to be $H$. pylori negative by tissue examination (negative culture or histology), the mean ODR-value plus 3 intervals of standard deviation (SD) from those animals was used to define the threshold for negativity (0.34). For IgA, the mean value of 9 uninfected monkeys plus 2 intervals of SD was used to define the threshold for negativity (0.44). An ELISA to detect anti-CagA IgG in plasma from the monkeys was performed using a purified recombinant CagA antigen, as described [48]. The assay was modified with the use of a goat anti-monkey IgG (gamma chain) conjugate. The monkey plasma was diluted 1:100. A cutoff value was established to distinguish between positive and negative CagA results based on the 9 monkeys found by tissue exam to be $H$. pylori-negative. The mean value plus 2 intervals of SD for the 9 animals was used to define the threshold for positivity $(0.20)$.

Measurement of $\boldsymbol{H}$. pylori-specific antibodies in Cohort 2 For cohort 2, ELISAs were performed as described above. Each sample was tested twice and in the case of disparate results, a third measurement was performed. If samples had discordant ODR-values in the two runs (values close to the negative and positive controls, respectively), we assumed that at least one value was an artifact, and the assay repeated. An assay also was repeated when the ODR-values were close to the threshold values. Resulting ODRs were averaged and evaluated using the determined cut-off values from the reference values from Cohort 1. Additionally, Cohort 2 values were statistically analyzed to evaluate whether the same cut-off values could be obtained without using the reference group. To obtain the cut-off for positive samples, the mean of ODRs between 0.4-1.0 was calculated and 2 times the SD was subtracted, providing a cut-off for positivity (a summary of all values is provided in Table 3 ). To determine the negative cut-off, the mean of ODRs between 0.000-0.299 was calculated and two times the SD was added. Values between 0.300-0.399 were only excluded for the statistical analysis of the cut-off values. After establishing the cut-off values for positivity and negativity, ODRs between 0.300-0.399 were assigned according to these values.

\section{C. jejuni ELISAs}

Since antigens from sonicated whole $C$. jejuni cells did not yield reliable results for serology (not shown), the McCoy antigen [49] (from PEN1, 2, and 3 strains), as described [49,50], was used for IgG and IgA determination. In brief, $C$. jejuni cells were harvested in sterile water, washed twice with water and $0.1 \mathrm{~g}$ of wet cells were suspended in $2.5 \mathrm{ml} 0.2 \mathrm{M}$ glycine-hydrochloride buffer ( $\mathrm{pH}$ 2.2). Suspensions were stirred at $25^{\circ} \mathrm{C}$ for $15 \mathrm{~min}$ and centrifuged at $11,000 \mathrm{x} \mathrm{g}$ for $15 \mathrm{~min}$. The supernatant was collected and sodium hydroxide was added to neutralize the suspension. Next, the suspension was dialyzed against water for $24 \mathrm{~h}$ at $4^{\circ} \mathrm{C}$ and the protein concentration was determined. ELISA was performed as described for $H$. pylori. Monkey sera were diluted 1:200 and goat anti-monkey IgG (gamma chain) or IgA (alpha chain) conjugated to horseradish peroxidase (Rockland Immunochemicals Inc., Gilbertsville, PA) (1:2000) was used as the secondary antibody. $\mathrm{OD}_{405}$ values were normalized using a known positive human control serum (1:200) to compare ODR. Each sample was tested 2-3 times, as described above.

\section{Determination of cut-off values for $C$. jejuni lgG ELISAs}

To initially determine a range to examine seropositivity, the mean of sera with ODRs between 0.000-0.299 was calculated and 2 intervals of SD were added, obtaining an initial negative cut-off of 0.338 . Next, the mean of ODRs between 0.4-1.0 was calculated and 2 SD intervals substracted resulting in a positive cut-off of 0.318 . We also used 10 serum samples from $C$. jejuni-positive 
persons and 16 serum samples from $C$. jejuni-negative persons. The calculated negative cut-off was 0.362 and the positive was 0.418 . We calculated the mean value for these three tentative cut-offs, and established a cut-off of 0.340 as an alternative means to define the thresholds for positivity and negativity.

\section{Determination of cut-off values for C. jejuni IgA ELISAs}

IgA cut-offs were calculated as described for IgG. Since the negative cut-off was 0.368 and the positive cut-off was 0.326 , we used a cut-off of 0.350 to analyze Cohort 2 .

\section{Competing interests}

The authors declare that they have no competing interests.

\section{Authors' contributions}

SK participated in the study design, carried out experiments, analyzed the data and drafted the manuscript. GPP carried out experiments and analyzed the data from cohort 1. JLRC and RTA performed immunoassays and helped to analyze the data. HL participated in the statistical analysis of the data. AD created and designed the study and analyzed the biopsies, JAGM provided plasma samples. MGDB and MJB participated in the design of the study and helped to analyze the data and to draft the manuscript. All authors read and approved the final manuscript.

\section{Acknowledgements}

This paper is dedicated to the memory of our colleague, Andre Dubois, M.D., Ph.D., who was deeply involved with the creation of this study and its conduct, but who did not survive until its publication. We remember Andre as a true scientist and a great friend.

This study was supported by RO 1GM6370 (MJB), RR003640 (Caribbean Primate Research Center, University of Puerto Rico-Medical Sciences Campus) and the MBRS-RISE Program of the University of Puerto Rico at Rio Piedras (JLRC), 5P20RR016470 (RTA) and 8P20GM103475 (RTA) from the National Institutes of Health, the Bill and Melinda Gates Foundation and the Diane Belfer Program in Human Microbial Ecology (MJB), the Michael Saperstein Medical Scholars Program (SK).

\section{Author details}

'Department of Medicine, NYU Langone Medical Center, New York, NY, USA. ${ }^{2}$ Department of Microbiology, NYU Langone Medical Center, New York, NY, USA. ${ }^{3}$ VA Medical Center, New York, NY, USA. ${ }^{4}$ Department of Population Health, NYUSOM, New York, NY, USA. ${ }^{5}$ Department of Biology, University of Puerto Rico, San Juan, PR, USA. Interamerican University of Puerto Rico, Metropolitan Campus, San Juan, PR, USA. 'Digestive Diseases Division, Department of Medicine, Uniformed Services of the Health Sciences, Bethesda, MD, USA. ${ }^{8}$ Caribbean Primate Research Center, University of Puerto Rico-Medical Sciences Campus, San Juan, PR, USA.

Received: 9 July 2012 Accepted: 17 August 2012

Published: 24 August 2012

\section{References}

1. Perez-Perez Gl, Salomaa A, Kosunen TU, Daverman B, Rautelin H, Aromaa A, Knekt $P$, Blaser MJ: Evidence that $\operatorname{cag} A(+)$ Helicobacter pylori strains are disappearing more rapidly than cagA(-) strains. Gut 2002, 50:295-298.

2. Banatvala N, Mayo K, Megraud F, Jennings R, Deeks JJ, Feldman RA: The cohort effect and Helicobacter pylori. J Infect Dis 1993, 168:219-221.

3. Mishra S, Singh V, Rao GR, Dixit VK, Gulati AK, Nath G: Prevalence of Helicobacter pylorin asymptomatic subjects-a nested PCR based study. Infect Genet Evol 2008, 8:815-819.

4. Ahmed KS, Khan AA, Ahmed I, Tiwari SK, Habeeb A, Ahi JD, Abid Z, Ahmed N, Habibullah CM: Impact of household hygiene and water source on the prevalence and transmission of Helicobacter pylori: a South Indian perspective. Singapore Med J 2007, 48:543-549.

5. Kumagai T, Malaty HM, Graham DY, Hosogaya S, Misawa K, Furihata K, Ota $H$, Sei C, Tanaka E, Akamatsu T, et al: Acquisition versus loss of Helicobacter pylori infection in Japan: results from an 8-year birth cohort study. J Infect Dis 1998, 178:717-721.

6. Goodman KJ, Correa P, Tengana Aux HJ, Ramirez H, DeLany JP, Guerrero Pepinosa O, Lopez Quinones M, Collazos Parra T: Helicobacter pylori infection in the Colombian Andes: a population-based study of transmission pathways. Am J Epidemiol 1996, 144:290-299.

7. Ernst PB, Gold BD: The disease spectrum of Helicobacter pylori: the immunopathogenesis of gastroduodenal ulcer and gastric cancer. Annu Rev Microbiol 2000, 54:615-640.

8. Chen Y, Blaser MJ: Inverse associations of Helicobacter pylori with asthma and allergy. Arch Intern Med 2007, 167:821-827.

9. Chen Y, Blaser MJ: Helicobacter pylori colonization is inversely associated with childhood asthma. J Infect Dis 2008, 198:553-560.

10. Arnold IC, Dehzad N, Reuter S, Martin H, Becher B, Taube C, Muller A: Helicobacter pylori infection prevents allergic asthma in mouse models through the induction of regulatory T cells. J Clin Invest 2011, 121:3088-3093.

11. Higgins $P D$, Johnson LA, Luther J, Zhang M, Sauder KL, Blanco LP, Kao JY: Prior Helicobacter pylori infection ameliorates Salmonella typhimuriuminduced colitis: Mucosal crosstalk between stomach and distal intestine. Inflamm Bowel Dis 2011, 17:1398-1408.

12. Cohen D, Shoham O, Orr N, Muhsen K: An inverse and independent association between Helicobacter pylori infection and the ncidence of shigellosis and other diarrheal diseases. Clin Infect Dis 2012, 54:e35-42.

13. Dubois A, Fiala N, Heman-Ackah LM, Drazek ES, Tarnawski A, Fishbein WN, Perez-Perez Gl, Blaser MJ: Natural gastric infection with Helicobacter pylori in monkeys: a model for spiral bacteria infection in humans. Gastroenterology 1994, 106:1405-1417.

14. Drazek ES, Dubois A, Holmes RK: Characterization and presumptive identification of Helicobacter pylori isolates from rhesus monkeys. J Clin Microbiol 1994, 32:1799-1804.

15. Allos BM: Campylobacter jejuni Infections: update on emerging issues and trends. Clin Infect Dis 2001, 32:1201-1206.

16. Dingle KE, Van Den Braak N, Colles FM, Price LJ, Woodward DL, Rodgers FG, Endtz HP, Van Belkum A, Maiden MC: Sequence typing confirms that Campylobacter jejuni strains associated with Guillain-Barre and MillerFisher syndromes are of diverse genetic lineage, serotype, and flagella type. J Clin Microbiol 2001, 39:3346-3349.

17. Yuki N, Tagawa Y, Irie F, Hirabayashi Y, Handa S: Close association of Guillain-Barre syndrome with antibodies to minor monosialogangliosides GM1b and GM1 alpha. J Neuroimmunol 1997, 74:30-34.

18. Moran AP, Prendergast MM: Molecular mimicry in Campylobacter jejuni lipopolysaccharides and the development of Guillain-Barre syndrome. J Infect Dis 1998, 178:1549-1551.

19. Andrade MC, Gabeira SC, Abreu-Lopes D, Esteves WT, Vilardo Mde C, Thome JD, Cabello PH, Lauria-Filgueiras AL: Circulation of Campylobacter spp. in rhesus monkeys (Macaca mulatta) held in captivity: a longitudinal study. Mem Inst Oswaldo Cruz 2007, 102:53-57.

20. Solnick JV, Chang K, Canfield DR, Parsonnet J: Natural acquisition of Helicobacter pylori infection in newborn rhesus macaques. J Clin Microbiol 2003, 41:5511-5516.

21. Boonjakuakul JK, Canfield DR, Solnick JV: Comparison of Helicobacter pylori virulence gene expression in vitro and in the Rhesus macaque. Infect Immun 2005, 73:4895-4904

22. Mattapallil JJ, Dandekar S, Canfield DR, Solnick JV: A predominant Th1 type of immune response is induced early during acute Helicobacter pylori infection in rhesus macaques. Gastroenterology 2000, 118:307-315.

23. Solnick JV, Hansen LM, Salama NR, Boonjakuakul JK, Syvanen M: Modification of Helicobacter pylori outer membrane protein expression during experimental infection of rhesus macaques. Proc Natl Acad Sci U S A 2004, 101:2106-2111.

24. Styer CM, Hansen LM, Cooke CL, Gundersen AM, Choi SS, Berg DE, Benghezal M, Marshall BJ, Peek RM Jr, Boren T, Solnick JV: Expression of the BabA adhesin during experimental infection with Helicobacter pylori. Infect Immun 2010, 78:1593-1600.

25. Dabiri H, Maleknejad P, Yamaoka Y, Feizabadi MM, Jafari F, Rezadehbashi M, Nakhjavani FA, Mirsalehian A, Zali MR: Distribution of Helicobacter pylori cagA, cagE, oipA and vacA in different major ethnic groups in Tehran, Iran. J Gastroenterol Hepatol 2009, 24:1380-1386.

26. Contreras M, Pujol FH, Perez-Perez Gl, Marini E, Michelangeli FA, Ponce L, Dominguez-Bello MG: Helicobacter pylori seroprevalence in Amerindians from isolated locations. Am J Trop Med Hyg 2008, 78:574-576. 
27. Torres J, Camorlinga-Ponce M, Perez-Perez G, Munoz L, Munoz O: Specific serum immunoglobulin $\mathrm{G}$ response to urease and CagA antigens of Helicobacter pylori in infected children and adults in a country with high prevalence of infection. Clin Diagn Lab Immunol 2002, 9:97-100.

28. Perez-Perez Gl, Cohn DL, Guerrant RL, Patton CM, Reller LB, Blaser MJ: Clinical and immunologic significance of cholera-like toxin and cytotoxin production by Campylobacter species in patients with acute inflammatory diarrhea in the USA. J Infect Dis 1989, 160:460-468.

29. Blaser MJ, Black RE, Duncan DJ, Amer J: Campylobacter jejuni-specific serum antibodies are elevated in healthy Bangladeshi children. J Clin Microbiol 1985, 21:164-167.

30. Blaser MJ, Taylor DN, Echeverria P: Immune response to Campylobacter jejuni in a rural community in Thailand. J Infect Dis 1986, 153:249-254.

31. Timmins RJ, Richardson M, Chhangani A, Yongcheng L: Macaca mulatta. In IUCN 2012. IUCN Red List of Threatened Species. Version 2012.1, 2008. [www.iucnredlist.org]. Downloaded on 20 August 2012

32. Shedlock DJ, Silvestri G, Weiner DB: Monkeying around with HIV vaccines: using rhesus macaques to define 'gatekeepers' for clinical trials. Nat Rev Immunol 2009, 9:717-728.

33. Edghill-Smith Y, Golding H, Manischewitz J, King LR, Scott D, Bray M, Nalca A, Hooper JW, Whitehouse CA, Schmitz JE, et al: Smallpox vaccine-induced antibodies are necessary and sufficient for protection against monkeypox virus. Nat Med 2005, 11:740-747.

34. Sparman M, Dighe V, Sritanaudomchai H, Ma H, Ramsey C, Pedersen D, Clepper L, Nighot P, Wolf D, Hennebold J, Mitalipov S: Epigenetic reprogramming by somatic cell nuclear transfer in primates. Stem Cells 2009, 27:1255-1264.

35. Byrne JA, Pedersen DA, Clepper LL, Nelson M, Sanger WG, Gokhale S, Wolf DP, Mitalipov SM: Producing primate embryonic stem cells by somatic cell nuclear transfer. Nature 2007, 450:497-502.

36. Taylor DN, Echeverria P, Pitarangsi C, Seriwatana J, Bodhidatta L, Blaser MJ: Influence of strain characteristics and immunity on the epidemiology of Campylobacter infections in Thailand. J Clin Microbiol 1988, 26:863-868.

37. Perez-Perez GI, Blaser MJ: Conservation and diversity of Campylobacter pyloridis major antigens. Infect Immun 1987, 55:1256-1263.

38. Ng EK, Thompson SA, Perez-Perez Gl, Kansau I, van der Ende A, Labigne A Sung JJ, Chung SC, Blaser MJ: Helicobacter pylori heat shock protein A: serologic responses and genetic diversity. Clin Diagn Lab Immunol 1999, 6:377-382.

39. Gootz TD, Perez-Perez Gl, Clancy J, Martin BA, Tait-Kamradt A, Blaser MJ: Immunological and molecular characterization of Helicobacter felis urease. Infect Immun 1994, 62:793-798.

40. Suerbaum S, Josenhans C, Sterzenbach T, Drescher B, Brandt P, Bell M, Droge M, Fartmann B, Fischer HP, Ge Z, et al: The complete genome sequence of the carcinogenic bacterium Helicobacter hepaticus. Proc Natl Acad Sci U S A 2003, 100:7901-7906.

41. Perez-Perez GI, Dworkin BM, Chodos JE, Blaser MJ: Campylobacter pylori antibodies in humans. Ann Intern Med 1988, 109:11-17.

42. Perez-Perez Gl, Taylor DN, Bodhidatta L, Wongsrichanalai J, Baze WB, Dunn $\mathrm{BE}$, Echeverria PD, Blaser MJ: Seroprevalence of Helicobacter pylori infections in Thailand. J Infect Dis 1990, 161:1237-1241.

43. Faulde M, Putzker M, Mertes T, Sobe D: Evaluation of an immunofluorescence assay for specific detection of immunoglobulin G antibodies directed against Helicobacter pylori, and antigenic crossreactivity between $\mathrm{H}$. pylori and Campylobacter jejuni. J Clin Microbiol 1991, 29:323-327.

44. Karvar S, Karch H, Frosch M, Burghardt W, Gross U: Use of serum-specific immunoglobulins $A$ and $G$ for detection of Helicobacter pylori infection in patients with chronic gastritis by immunoblot analysis. J Clin Microbiol 1997, 35:3058-3061.

45. Vorobjova T, Nilsson I, Kull K, Maaroos HI, Covacci A, Wadstrom T, Uibo R: CagA protein seropositivity in a random sample of adult population and gastric cancer patients in Estonia. Eur J Gastroenterol Hepatol 1998, 10:41-46.

46. Solnick JV, Fong J, Hansen LM, Chang K, Canfield DR, Parsonnet J: Acquisition of Helicobacter pylori infection in rhesus macaques is most consistent with oral-oral transmission. J Clin Microbiol 2006, 44:3799-3803.

47. Dubois A, Berg DE, Incecik ET, Fiala N, Heman-Ackah LM, Perez-Perez Gl, Blaser MJ: Transient and persistent experimental infection of nonhuman primates with Helicobacter pylori: implications for human disease. Infect Immun 1996, 64:2885-2891.
48. Blaser MJ, Perez-Perez Gl, Kleanthous H, Cover TL, Peek RM, Chyou PH, Stemmermann GN, Nomura A: Infection with Helicobacter pylori strains possessing CagA is associated with an increased risk of developing adenocarcinoma of the stomach. Cancer Res 1995, 55:2111-2115.

49. McCoy EC, Doyle D, Burda K, Corbeil LB, Winter AJ: Superficial antigens of Campylobacter (Vibrio) fetus: characterization of antiphagocytic component. Infect Immun 1975, 11:517-525.

50. Blaser MJ, Duncan DJ: Human serum antibody response to Campylobacter jejuni infection as measured in an enzyme-linked immunosorbent assay. Infect Immun 1984, 44:292-298.

doi:10.1186/1757-4749-4-9

Cite this article as: Kienesberger et al:: Serologic host response to Helicobacter pylori and Campylobacter jejuni in socially housed Rhesus macaques (Macaca mulatta). Gut Pathogens 2012 4:9.

\section{Submit your next manuscript to BioMed Central and take full advantage of:}

- Convenient online submission

- Thorough peer review

- No space constraints or color figure charges

- Immediate publication on acceptance

- Inclusion in PubMed, CAS, Scopus and Google Scholar

- Research which is freely available for redistribution

Submit your manuscript at www.biomedcentral.com/submit
C) Biomed Central 